\title{
Meta-Analysis of EMF-Induced Pollution by COVID-19 in Virtual Teaching and Learning With an Artificial Intelligence Perspective
}

\author{
Sanjita Das, Noida Institute of Engineering and Technology, Pharmacy Institute, India \\ Shilpa Srivastava, Christ University, Delhi, India \\ Aprna Tripathi, Vellore Institute of Technology, Bhopal, India \\ Saumya Das, Noida Institute of Engineering and Technology, Pharmacy Institute, India
}

\begin{abstract}
Concerns about the health effects of frequent exposure to electromagnetic fields (EMF) emitted from mobile towers and handsets have been raised because of the gradual increase in usage of cell phones and frequent setting up of mobile towers. The present study is targeted to detrimental effects of EMF radiation on various biological systems mainly due to online teaching and learning processes by suppressing the immune system. During the COVID-19 pandemic, the increased usage of internet due to online education and online office leads to more detrimental effects of EMF radiation. Further inculcation of soft computing techniques in EMF radiation has been presented. A literature review focusing on the usage of soft computing techniques in the domain of EMF radiation has been presented in the article. An online survey has been conducted targeting Indian academic stakeholders (specially teachers, students, and parents termed as population in the paper) for analyzing the awareness towards the biohazards of EMF exposure.
\end{abstract}

\section{KEYWORDS}

AI, COVID-19, EMF Radiation, Internet and Online-Education, Machine Learning, Mobile Phones, Mobile Towers

\section{INTRODUCTION}

Now-a-days cell phones are considered as the most pleasant asset for all human being from kids to old age has. It has become the basic need of today for which the growth of mobile industry in India has been increased enormously in an uncontrolled rate during the last decade. After the occurrence of COVID-19 pandemic, it became an essential tool for education. But unfortunately, the main sources of EMF radiations are cell phones and mobile towers. EMFs are categorized into two groups by their frequency: non-ionizing with low-level radiation mostly without biological harm and ionizing with high-level radiation causing cellular and DNA damage.

In the present contest of COVID-19 pandemic forced many countries to shut down their economic activities, education and sports to reduce the spread of the virus. It changed the whole world into online activities like online office, online classes of schools, colleges and couching for children, online conferences, webinars, interviews, official meetings, etc. to maintain social distancing. According to estimates many new 5G base stations on Earth and 20,000 new satellites in space, 200 billion transmitting objects would be introduced for improving the Internet in 2020, which may be

\section{DOI: 10.4018/IJWLTT.285566}

This article published as an Open Access article distributed under the terms of the Creative Commons Attribution License (http://creativecommons.org/licenses/by/4.0/) which permits unrestricted use, distribution, and production in any medium, provided the author of the original work and original publication source are properly credited. 
increased to trillions in future. By all these up gradations with extremely high frequencies no living being on Earth will be able to avoid exposure, 24 hours a day, 365 days a year, there will be tens to hundreds of times greater exposure than what exists today, without any possibility of escape anywhere on the planet. These 5G plans will generate serious, irreversible hazards to the living being and the ecosystem. Mainly, the safety limits are set well below harm causing levels (Karaboytcheva, 2020).

Though mobile phones have numerous utilities and benefits in attending the classes, getting course and college updates through various applications, it has its drawbacks as every technology has some positive as well as negative impacts. Due to random and excessive use of mobile phones and mushrooming around of giant mobile towers, health risks associated with cell phones and mobile towers have become a growing concern. According to WHO, mobile phones may increase the risk of brain and spine tumors, cancer cases, downs the immunity, headaches, sleep disturbances, fatigue, lack of concentration, memory loss, vision distortion, joint pains, heart problems, miscarriage and so on in last 5 to 10 years. Many people are unaware of the harmful effects of the cell phone radiation and its prevention measures when their cell phones are in standby mode. Various epidemiological and experimental studies have been carried out and observed the biological adverse effects of electromagnetic radiation and observed an increase in short-term and long-term diseases (Bortkiewicz, 2019; Vijay et al., 2017; Prakash et al., 2016).

Usage of mobile in studies has their own benefits but the drawbacks cannot be overlooked. Due to the COVID-19, almost all the academic institutions adopted the online mode for classes and now the negative impacts on health come in the picture. The studies show that most students are feeling the strain, for many strains begin with the eyes. Due to continued usage of mobile and internet students are feeling more anxiety and stress that can lower immunity.

Taking all the above-mentioned points into consideration, the present study has been planned and carried out to achieve at the definite goal and desired outcome. The study was focused on the major harmful effects due to the exposure to EMF radiation and application of Artificial Intelligence for their management. The study was then progressed towards the raised harm due to increased use of internet and mobile phones in COVID-19 pandemic in education system by the help of meta-analysis and finding out the means to overcome their detrimental effects.

For the reduction of EMF exposure and its awareness the study inculcates the concept of AI techniques in the assessment of EMF radiation as well as diagnosis of the diseases induced by the EMF radiation. The usage of these techniques helps the system for the early detection of harmful radiations so that preventive measures can be taken in this regard. With the advancement of machine learning and deep learning there is a remarkable contribution in every sector and so the environment domain. For the assessment of EMF induced diseases raised by decrease in immunity, cancer, cardiovascular, psychological, and genetic disorders etc. are taken into consideration. A number of researchers reported the down immunity due the exposure to EMF which is also adding management of COVID-19 occurrence. It has been reported that the EMF radiations deviate the cell signals and these factors activate the danger signals and innate immunity cells hence, downs the immunity (Rosado et al., 2018). A study on human addressed the cognitive function change as a consequence of radio frequency EMF coverage (Curcio et al., 2019). In accordance with their view, and Meta analyses, it confirmed the paucity of evidence and the lack of reliability of psychomotor and cognitive effects of acute RF EMF exposure on human volunteers (Malik et al., 2020). realizes the health dangers develop from use of cellular communication and explored the possible biological impacts of EMF introduction on human brain.

The present study is mainly targeted the review on the EMF radiation generated untoward effects on human health which has been increased due to enhanced internet and mobile phone use during the COVID-19 pandemic. As a preventive measure the application of Artificial Intelligence was incorporated for their management. In this support one survey was undertaken and the metaanalysis was carried out for better understanding. The total study was carried out to aware the society 
about these increased health hazards due to increased EMF exposure with main purpose of the socioeconomic benefits.

\section{HEALTH HAZARDS BY EMF RADIATIONS}

- Okechukwu (2020) reported significant alteration of neurophysiological mechanisms by RFEMF exposure based on electroencephalogram studies and molecular and biochemical analysis.

- Sultangaliyeva, et al. (2020) studied behavioral patterns of animals in response to the influence of cell phones and observed that the motor component of behavior is suppressed.

- Levitt \& Lai (2010) worked on the biological effects of EMF radiation emitted by cell tower base stations and other antenna arrays and observed that these are one of the fastest growing forms of environmental pollution is non-ionizing electromagnetic fields.

- Miller et al. (2019) studied the radio-frequency radiation emitted by cell phones and other wireless devices. They recommended supportive measures to reduce all exposures to RFR (Radio Frequency Radiation) to the population that have a cell phone next to the body by providing warning from the governments, public health authorities, and physicians/allied health professionals about its harmful effects.

- Rosado et al. (2018) reported that the effects of extremely low frequency (ELF)-EMF and pulsed EMF on cell signals and factors activate the danger signals and innate immunity. Danger signals stimulate an immune response, but also activating mechanisms that (later on) will negatively regulate immune cell activation.

- Kivrak et al. (2017) observed an increase of free radical concentrations and traceability due to the exposure to electromagnetic fields which can affect the radical couple recombination.

- Prakash et al. (2016) investigated a case study from Bangalore on the harmful effects of mobile tower radiations on human health and observed headache, irritability, nausea, appetite loss, decreased immunity, discomfort, sleep disturbance, depression, memory loss, difficulty in concentration and dizziness, etc. in the exposed groups and suggested cell phones and cell phone tower radiation are strong risk factors factor for high exposure to human head and its sensitivity to brain tissue.

- Angelo et al. (2015) worked on the experimental model for ELF-EMF exposure concerning human health and observed that different modifications of the expression of MCP-1 in different cell types due to EMF-exposure and suggested for additional studies the MCP-1 expression.

- Sharma \& Singh (2014) investigated in the district of Greater Noida, Uttar Pradesh, India for the experimental study of the signal strength measurements in a typical worldwide interoperability for microwave access network operating at $2.62 \mathrm{GHz}$ installed for fixed wireless access. For deriving characteristic parameters of the radio propagation environment, the experimental data were analyzed.

- $\quad$ Singh \& Kaur (2014) and Singh and Kapoor, 2014 studied the biological implications of EMF on various life forms and suggested proper scientific investigations to follow the precautionary principle and limit their exposure and to devise a strategy to prevent the health hazards due to EMFs.

- $\quad$ Pachuau \& Pachuau (2014) studied the health hazards of cell tower radiation measuring different health symptoms based on sex faced by the inhabitants within $50 \mathrm{~m}$ and outside $50 \mathrm{~m}$ and found more health complaints with the inhabitants living within $50 \mathrm{~m}$ than those living outside $50 \mathrm{~m}$ and more in females.

- Research like Jouni et al. (2012), had investigated the involvement of free radical processes in the genetic effects of EMF (ELF-EMF).

- $\quad$ Karaca et al. (2012) reported their investigation on genotoxic effects of radiofrequency (RF) waves in an in- vitroexperimental brain cell culture model of mice. 
- Several researchers had also reported the long term/repeated exposure studies of RFR on various animal models (Garaj-Vrhovac et al. (2011), Guler et al. (2012). These data reflect the biological effects of EMF exposure in real life situation, since human environmental EMF exposure is both chronic and intermittent.

- Atasoy et al. (2012) and Avendano et al. (2012) had reported separately that RFR might affect reproduction mainly on sperm physiology and DNA.

- $\quad$ Atasoy et al. (2012), Campisi et al. (2010), Garaj-Vrhovac et al. (2011), Guleret al. (2010), Kesari et al. (2010), Khalil et al. (2012), Kumar et al. (2010), Tomruket al. (2010) and Xu et al. (2010) had observed that after EMF exposure in cells of experimental animals there was increase in free radical activity and changes in enzymes involved in cellular oxidative processes.

- El-Bialy et al., (2013) and Journiet al., (2012) observed that EMF could interact with other environmental entities causing synergistically genetic effects. Those entities included ELF-EMFCisplastin (Extremely Low-Frequency-Electromagnetic Field), ionizing radiation, etc. Most of the compounds that interacted with EMF were mutagens to which a person is usually exposed simultaneously and should be considered more seriously.

- Campisi et al. (2010) reported acute exposure to a 50-Hz amplitude-modulated 900-MHz RFR caused increase in free radical activity and DNA fragmentation in brain cells, whereas there was no effect due to a continuous wave $9000-\mathrm{MHz}$ field.

- Franzellitti et al. (2010) investigated that after exposure to a 217-Hz modulated $1.8 \mathrm{GHz}-\mathrm{RFR}$ increase in DNA strand breaks in trophoblasts, whereas there was no effect at a continuous-wave field of the same carrier frequency.

\section{APPLICATIONS OF ARTIFICIAL INTELLIGENCE IN THE BIOHAZARDS OF EMF RADIATIONS}

The recent studies on the usage of AI techniques for the analysis of EMF radiation and for the detection of the diseases caused by the EMF radiation are also studied. The public concern on potential health risks from power-frequency fields and from RF radiation emissions from wireless communications has been increasing during recent years. There has been a remarkable improvement in many domains with the inculcation of techniques like AI, machine learning, deep learning, fuzzy logic etc. The applications of these techniques for analyzing the effects of EMF radiation and the diagnosis of diseases caused by these radiations like decreasing immunity, genetic disorders, cancer, infertility, cardiovascular diseases and psychological issues are discussed in this article.

Wang \& Wiart (2020) analyzed that the usage of artificial neural networks in the mapping of space and time of the exposure caused by electromagnetic field due to cellular base stations. In addition to this the impact of city architecture on EMF exposure reconstruction is accessed and strength of ANN (Artificial Neural Networks) is evaluated when the system is exposed to addition of noise. Tognola et al. (2019) applied machine learning approach called Cluster analysis on the 977 children of France for characterizing the situation based on real life EMF exposure. The purpose of Cluster analysis is to discover variables for best categorization of the exposure scenarios. Singh et al. (2020) applied machine learning technique for identifying the affect of EMF exposure implicitly on the changes in brain morphology considering drosophila melanogaster as a specimen. The devised method is a novel approach with low time complexity and subsequently it provides an efficient image processing framework. Boumaizaet al.,(2015) made use of Fuzzy logic for analyzing and predicting the pollution caused by electromagnetic in Algeria. The purpose of Sasaet al.(2019) was to measure and evaluate the electromagnetic field for assessing the exposure. Further the obtained data was compared with the previous literature review based on effects of EMF on public health. Because of the uncertainty and imprecision involved in this process it was found to be appropriate to use Fuzzy logic for the analysis. The application of Fuzzy logic was found to be perfect for predicting the health effects on exposed subjects. The application using fuzzy logic for analyzing the effects of electric field exposure 
was discussed by Lolea \& Dzitac (2018). The results of electric field strength measurements into a power substation and the fuzzy toolbox existing in the Matlab software were used for achieving this purpose. Ioan et al. (2019) aimed towards the increasing the accuracy of the EMF effects assessment on people who are exposed to stabilized regime areas of power plants. Along with this the usage of fuzzy approach for accessing the severity of EMF exposure has also been discussed. Further, the application of fuzzy logic can also been seen in the study of Kosalayet al.(2010)where focus is towards calculating the RF electromagnetic fields which are out of the measurement points.It is achieved through the developed software, equipped with 3D screening unit. In a study (Comlekci et al., 2014) discussed briefly the assessment of health hazard due to electromagnetic radiation with the help of Fuzzy logic.

Besides the assessment and detection of hazards of EMF radiation these soft computing techniques also play an important role in the detection and diagnosis of the diseases caused due to EMF radiation. Following are some of the recent articles focussing on the detection and diagnosis of the health hazards based on genetic disorders, cancer, infertility, cardio vascular diseases and psychological issues. In a study (Srivastava et al., 2019)the authors have also illustrated the significance of AI, fuzzy logic, machine learning deep learning and artificial neural networks in analyzing the critical diseases. It is also well established by many co-workers the application of AI to estimate the modification in immunity of an individual which is very much useful in the present perspective of COVID-19 pandemic. Artificial Intelligence has shown a remarkable impact in diagnosing the Immune system in human body in the recent years. Through machine learning (ML), a branch of the wider field of artificial intelligence, it is possible to extract patterns within patient data, and exploit these patterns to predict patient outcomes for improved clinical management. Estimation of immunity state of an individual by AI is very much useful to fight against COVID-19 by enhancing the immunity prior to the infection. It can also be used to assess the extent of down immunity due to EMF radiation exposure by its increased access. Table 1 presents some of the recent studies in this domain.

\section{SURVEY ON EMF RADIATION}

There are many health hazards of EMF radiation. To know and understand the awareness of health implications an online survey has been conducted. The questionnaire is based on the different issues related to EMF radiation like their usage of mobile phones, residence location around mobile towers, awareness of harmful radiation through the use of mobile phones, and different types of EMF induced diseases etc.

\subsection{Criteria to Select the Responder}

The key objective of the survey is to identify the level of awareness about usage of mobile for education purpose and to run the awareness program for a specified category. Thus, the responders are selected on the following basis:

Age: Different age grouped people may have different level of awareness

Responder Type: Based on requirement to use mobile for education, responders are categorized into three categories - Student, Parent and Teacher.

Education Level: It is a common thought that educated people are more aware people. Thus, to find the truth of this, the education is taken a criterion.

Brief Discussion of Questionnaire: A set of twenty questions is asked to get the knowledge for the following issues:

- Distance between user's residence and mobile tower

- Average duration of use of mobile handset for studies

- Habits of Mobile usage

- Do you disable the data before going to sleep 
Table 1. Application of Al in detection of diseases

\begin{tabular}{|c|c|c|c|}
\hline Health hazard & \multicolumn{2}{|c|}{ Objective } & Technique \\
\hline \multirow[t]{3}{*}{ Immunity } & 1 & $\begin{array}{l}\text { Stafford et al., (2020) surveyed the use of ML methods to address clinical problems } \\
\text { in autoimmune disease. }\end{array}$ & $\begin{array}{l}\text { Machine } \\
\text { learning }\end{array}$ \\
\hline & 2 & $\begin{array}{l}\text { - Jabbari \& Rezaei, (2019) reported the application of Artificial Intelligence on the } \\
\text { human immune system like antigen and phenotype detection, predicting prognosis } \\
\text { and treatment outcomes. }\end{array}$ & $\begin{array}{l}\text { Artificial } \\
\text { Intelligence }\end{array}$ \\
\hline & 3 & $\begin{array}{l}\text { - Yang et al., (2014) suggested the usage of Artificial Immune System based ID } \\
\text { methods by presenting a framework. This framework is on the three core aspects: } \\
\text { antibody/antigen encoding, generation algorithm and evolution mode. }\end{array}$ & $\begin{array}{l}\text { Artificial } \\
\text { Intelligence }\end{array}$ \\
\hline \multirow[t]{12}{*}{ Cancer } & 1 & $\begin{array}{l}\text { The purpose of the study is to propose a predictive model for the diagnosis of } \\
\text { ovarian cancer (Lu et al., 2020). }\end{array}$ & \multirow[t]{4}{*}{$\begin{array}{l}\text { Machine } \\
\text { learning }\end{array}$} \\
\hline & 2 & $\begin{array}{l}\text { According to one findings of in cancer boosted decision tree algorithm can be used } \\
\text { for achieving best classification accuracy (Alabi et al., 2020). }\end{array}$ & \\
\hline & 3 & $\begin{array}{l}\text { This aim of this study is to provide make use of machine learning technique for } \\
\text { detecting breast cancer. An experimental analysis was performed on a data set for } \\
\text { evaluating the performance and it was found that the results of proposed method his } \\
\text { more accurate and efficient as compared to the existing methods (Vaka et al.,2020). }\end{array}$ & \\
\hline & 4 & $\begin{array}{l}\text { According to the study of Juwara et al., } 2020 \text { the predictive factors for neuropathic } \\
\text { pain after breast cancer surgery was identified with the help of machine learning. It } \\
\text { was analyzed that Penalized regression methods and the Gradient boosting model } \\
\text { are more efficient as compared to other models. }\end{array}$ & \\
\hline & 5 & $\begin{array}{l}\text { A detailed review regarding the applications of different artificial techniques such as } \\
\text { machine learning, deep learning in developing anti cancer drug has been presented } \\
\text { in (Guosheng et al., 2020) }\end{array}$ & \multirow[t]{3}{*}{$\begin{array}{l}\text { Artificial } \\
\text { Intelligence }\end{array}$} \\
\hline & 6 & $\begin{array}{l}\text { In the study of (Zakhem et al.,2020) the authors have assessed skin cancer with the } \\
\text { help of Artificial Intelligence and was observed to follow the trends in the field of } \\
\text { image recognition }\end{array}$ & \\
\hline & 7 & $\begin{array}{l}\text { The review presented by (Sechopoulos et al., 2020) aims towards providing } \\
\text { application, the basic concepts and developments of Artificial Intelligence in digital } \\
\text { mammography and digital breast tomosynthesis used for the detection of breast } \\
\text { cancer. }\end{array}$ & \\
\hline & 8 & $\begin{array}{l}\text { The purpose of this paper is to devise a hybrid structure that includes a double dep } \\
\text { transfer learning and interactive cross-task extreme learning machine for overcoming } \\
\text { the difficulties faced in breast histopathology images. It is based on feature } \\
\text { extraction and representation ability of CNN (Wang et al., 2020) }\end{array}$ & \multirow[t]{5}{*}{ Deep Learning } \\
\hline & 9 & $\begin{array}{l}\text { The review presented in this study (Pang et al., 2020) is based on the disease Breast } \\
\text { cancer which is one of the most frequent among women. The purpose is to present } \\
\text { the various deep learning methods for breast imaging with different modalities. }\end{array}$ & \\
\hline & 10 & $\begin{array}{l}\text { (Coccia, 2020) analysed the emerging applications of deep learning technology in } \\
\text { cancer imaging. }\end{array}$ & \\
\hline & 11 & $\begin{array}{l}\text { The authors of (Kadampur \& Riyaee, 2020) proposed a model-driven architecture } \\
\text { based on the AI technology- deep learning in the cloud for assisting in predicting } \\
\text { skin cancer with the approach of achieving better accuracy. }\end{array}$ & \\
\hline & 12 & $\begin{array}{l}\text { A novel deep learning (DL) model was devised for analysing and predicting the risk } \\
\text { for OS based on computed tomography (CT) images (Zhang et al., 2020). }\end{array}$ & \\
\hline
\end{tabular}


Table 1. Continued

\begin{tabular}{|c|c|c|c|}
\hline Health hazard & \multicolumn{2}{|c|}{ Objective } & Technique \\
\hline \multirow[t]{8}{*}{ Psychological Issues } & 13 & $\begin{array}{l}\text { The rise of machine learning techniques like Naïve Bayes, Support Vector Machine, } \\
\text { Logistic Regression, KNN, Neural Network and Convolutional Neural Network for } \\
\text { analysing and predicting ASD problems in children, adolescents and adults. Further } \\
\text { is has been observed that out of various techniques applied the results state that } \\
\text { CNN based prediction models perform better on the datasets with accuracy level } \\
\text { (Raj \& Masood, 2020). }\end{array}$ & \multirow[t]{3}{*}{$\begin{array}{l}\text { Machine } \\
\text { learning/ } \\
\text { Artificial } \\
\text { Intelligence }\end{array}$} \\
\hline & 14 & $\begin{array}{l}\text { Newer technologies which are based on machine learning and artificial intelligence } \\
\text { are making predictions possible at an individual patient level—-thus enabling for } \\
\text { personalizing treatments. This chapter summarized current state of evidence about } \\
\text { predictive biomarkers and mechanisms of treatment (non)response for anxiety } \\
\text { disordered patients (Lueken \& Hahn, 2020). }\end{array}$ & \\
\hline & 15 & $\begin{array}{l}\text { This chapter has provided the advantages of using AI-based technologies for clinical } \\
\text { psychology related treatments. A small introduction was given of the fundamental } \\
\text { process that uses machine learning technologies, a branch of AI about pattern } \\
\text { recognition, to make generalized predictions (Cummins et al., 2020). }\end{array}$ & \\
\hline & 16 & $\begin{array}{l}\text { The survey expounded most relevant neural network models of autism spectrum } \\
\text { disorder and schizophrenia, analysing from the initial connectionist models to } \\
\text { current deep neural network architectures (Lanillos et al., 2020). }\end{array}$ & $\begin{array}{l}\text { Neural } \\
\text { Networks }\end{array}$ \\
\hline & 17 & $\begin{array}{l}\text { Thepaper reviewed three main brain observation techniques which are used for study } \\
\text { of psychiatric disorders, magnetic resonance imaging, electroencephalography and } \\
\text { kinesics diagnoses—relating AI applications and algorithms to these. (Guang-DiLiu } \\
\text { et al., 2020] }\end{array}$ & $\begin{array}{l}\text { Artificial } \\
\text { Intelligence }\end{array}$ \\
\hline & 18 & $\begin{array}{l}\text { The authors suggested using theory to execute variable selection and data analyses } \\
\text { by utilizing machine learning in psychological research, they also include an } \\
\text { example from the cyberpsychology field (Delhai \& Montag, 2020). }\end{array}$ & \multirow[t]{2}{*}{$\begin{array}{l}\text { Machine } \\
\text { Learning }\end{array}$} \\
\hline & 19 & $\begin{array}{l}\text { The authors used the game and player statistics of PUBG players of Asian countries. } \\
\text { Subsequently, they run several state of the art supervised machine learning models } \\
\text { for predicting the event of IGD, ADHD, and GAD occurring. (Aggarwal et al., } \\
2020 \text { ) }\end{array}$ & \\
\hline & 20 & $\begin{array}{l}\text { The authors highlighted the path of the evolution of deep learning starting from } \\
\text { the connectionist project. This showed the remarkable continuity and highlights } \\
\text { differences. It considered how deep learning models are useful for a number of } \\
\text { cognitive topics, highlighting those where this has achieved a level of performance } \\
\text { which is comparable to humans, from perception to language (Perconti \& Plebe, } \\
\text { 2020) }\end{array}$ & Deep Learning \\
\hline
\end{tabular}


Table 1. Continued

\begin{tabular}{|c|c|c|c|}
\hline \multirow{2}{*}{$\begin{array}{l}\text { Health hazard } \\
\text { Cardiovascular }\end{array}$} & \multicolumn{2}{|c|}{ Objective } & \multirow{2}{*}{$\begin{array}{l}\text { Technique } \\
\text { Artificial } \\
\text { Intelligence }\end{array}$} \\
\hline & 21 & $\begin{array}{l}\text { The purpose of this review was to give insights about the applications of } \\
\text { AI in CVI imaging. It also included the strengths and limitations of the } \\
\text { deep learning approach in this regard (Xu et al., 2020). }\end{array}$ & \\
\hline & 22 & $\begin{array}{l}\text { The purpose of the study was to analyse the effect of cardiovascular color } \\
\text { doppler ultrasound imaging on application of artificial intelligence neural } \\
\text { network in the diagnosis of septic shock (Shen et al., 2020). }\end{array}$ & $\begin{array}{l}\text { Neural } \\
\text { Networks }\end{array}$ \\
\hline & 23 & $\begin{array}{l}\text { A detail literature review has been presented focusing on the usage } \\
\text { of machine learning in the treatment of cardiovascular diseases. The } \\
\text { application of ML has been shown in the predictive analysis and settings } \\
\text { of automated imaging interpretation, natural language processing and data } \\
\text { extraction from electronic health records (Kilic, 2020). }\end{array}$ & $\begin{array}{l}\text { Machine } \\
\text { learning }\end{array}$ \\
\hline & 24 & $\begin{array}{l}\text { The study throws light on application of AI for improving patient health } \\
\text { care from the perspective of a sonographer (Davis et al. 2020) }\end{array}$ & $\begin{array}{l}\text { Artificial } \\
\text { Intelligence }\end{array}$ \\
\hline & 25 & $\begin{array}{l}\text { The purpose of the study (Calvillo-Argüelles et al., 2020) was to use the } \\
\text { machine learning technique for optimizing the identification of patients } \\
\text { who experienced an in hospital cardio vascular event. }\end{array}$ & $\begin{array}{l}\text { Machine } \\
\text { learning }\end{array}$ \\
\hline & 26 & $\begin{array}{l}\text { In a study by (Wong et al., 2020) the focus was to discuss the diagnosis of } \\
\text { Cardiovascular diseases using the Artificial Intelligence technique. It has } \\
\text { thrown light on the paradigm shift of AI to Deep learning and analyses } \\
\text { the future of related machine intelligence applications in this domain }\end{array}$ & $\begin{array}{l}\text { Artificial } \\
\text { Intelligence }\end{array}$ \\
\hline & 27 & $\begin{array}{l}\text { A smart healthcare was proposed through the prediction of heart disease } \\
\text { using deep learning and feature fusion approaches (Ali et al., 2020). }\end{array}$ & $\begin{array}{l}\text { Deep } \\
\text { Learning }\end{array}$ \\
\hline & 28 & $\begin{array}{l}\text { The co-workers evaluated prognostic index for future cardiac events } \\
\text { among patient with cardiomyopathy by applying an artificial neural } \\
\text { networks (Currie et al., 2019). }\end{array}$ & $\begin{array}{l}\text { Neural } \\
\text { Networks }\end{array}$ \\
\hline & 29 & $\begin{array}{l}\text { The automatic detection of Coronary Heart Disease with the help of } \\
\text { Fuzzy rule based clinical system has been described by the authors of } \\
\text { (Kora et al., 2019). }\end{array}$ & Fuzzy logic \\
\hline \multirow[t]{3}{*}{ Genetical Disorders } & 30 & $\begin{array}{l}\text { The research (Javadiet al., 2019) had thrown light on the devising a deep } \\
\text { learning algorithm for the patients who are suffering from malfunction } \\
\text { malformation of sperm morphology. The purpose of machine learning } \\
\text { was to detect this malformation using human sperm cell images. }\end{array}$ & $\begin{array}{l}\text { Deep } \\
\text { Learning }\end{array}$ \\
\hline & 31 & $\begin{array}{l}\text { Deep learning approach was used to for the classification, automation, } \\
\text { standardization and accelerating the semen analysis. The study also } \\
\text { highlighted the importance of artificial intelligence technologies which } \\
\text { can exceed the accuracy, reliability, and efficiency of the system (Riordon } \\
\text { et al., 2019). }\end{array}$ & $\begin{array}{l}\text { Deep } \\
\text { Learning }\end{array}$ \\
\hline & 32 & $\begin{array}{l}\text { The purpose of (Beksaç et al., 1995) was to devise a smart system based } \\
\text { on artificial Intelligence technique for determining the genetical disorders } \\
\text { and fatal health problem by using maternal serum markers. }\end{array}$ & $\begin{array}{l}\text { Artificial } \\
\text { Intelligence }\end{array}$ \\
\hline
\end{tabular}


Table 2. Dataset categorization based on different criterion

\begin{tabular}{|l|l|l|}
\hline Criterion & Response Choice & No. of Responder \\
\hline \multirow{4}{*}{ Responder Type } & & \\
\cline { 2 - 3 } & Both(Teacher and Parent) & 54 \\
\cline { 2 - 3 } & Teacher & 26 \\
\cline { 2 - 3 } & Parents & 128 \\
\cline { 2 - 3 } & Students & 192 \\
\hline \multirow{4}{*}{ Education Level of Responder } & Ph.D. & 72 \\
\cline { 2 - 3 } & Post Graduate & 88 \\
\cline { 2 - 3 } & Graduate & 240 \\
\hline & $16-20$ & 172 \\
\cline { 2 - 3 } & $21-30$ & 136 \\
\cline { 2 - 3 } & $31-40$ & 68 \\
\cline { 2 - 3 } & Above 41 & 24 \\
\hline
\end{tabular}

- Do you disable the data when not in use/ or while travelling

- Awareness level about impacts on health because of high mobile usage

Data Set Description: At the prime level a survey is conducted at state level. The 400 responses are collected. The received is summarized in Table 2 .

\subsection{Analysis of Survey}

The questionnaire had twenty questions and was distributed among the teachers, students of different levels of schools and institutions along with the parents and educated residents of India (Figure 1 and Figure 4). There were total 400 responses which were analyzed to observe the awareness of health hazards due to EMF radiation. The responses obtained were found to be in the age group of above 2040 years of age (Figure 2) and out of them $70 \%$ are from NCR (National Capital Region) (Figure 3).

The observations reflect that only $39.6 \%$ population are residing at a distance of more than $300 \mathrm{~m}$ from the mobile tower though according to DOTEL/R/2019/50200/2 it should be 100m, 200m (Figure 5).Although $62.2 \%$ of respondents are aware that the distance from the mobile tower is an important factor for the occurrence of health hazards due to the radiation from the mobile towers (Figure 6).The duration of mobile use is maximum in the range of $2-4$ hours. $43.9 \%$, still in the category of 6-8 hours and above 8 hours collectively is around 29\% (Figure 7). It has been analyzed that more than $50 \%$ respondents don't disable their data while travelling (Figure 9) although 58.5\% they are aware that they are more prone to harmful radiation in travelling due the variation in the range of network coverage (Figure 8). Even in the case of sleeping only $49.3 \%$ disable their data to protect themselves from the harmful effects of radiation (Figure 9). Although $76.8 \%$ of total respondents know the harmful effects due to EMF exposure (Figure 8). Literature showed that global impacts of mobile applications are going high to engage in both purchasing and information-sharing activities causing approximately $10 \%$ of web site traffic and these should be used in good coverage area (Islam and Mazumder, 2010 and Taylor and Levin, 2014). (Figure 8) also states that 56\% are aware that usage of mobile apps is preferable in good network coverage. Only $29 \%$ of the responders were found to use hand free regularly whereas $28 \%$ never use the hand free (Figure 9) although $42 \%$ were aware of beneficial effects of using hand free (Figure 8). In the Indian scenario the use of internet for 4-6 hours is $71.4 \%$ and $32.8 \%$ by the children of age 3-7 years and $8-15$ years age group respectively. It 
International Journal of Web-Based Learning and Teaching Technologies Volume $17 \cdot$ Issue $4 \cdot$ July-August 2022

\section{Figure 1. Education details}

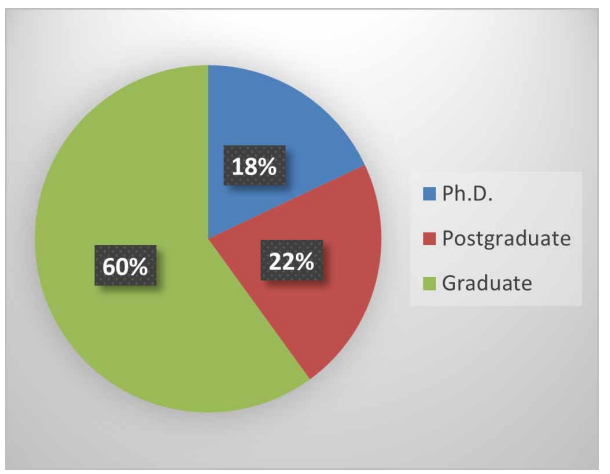

Figure 2. Age Group

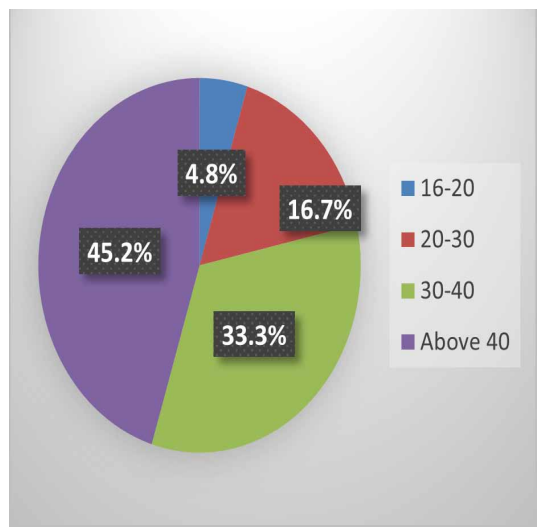

Figure 3. Location

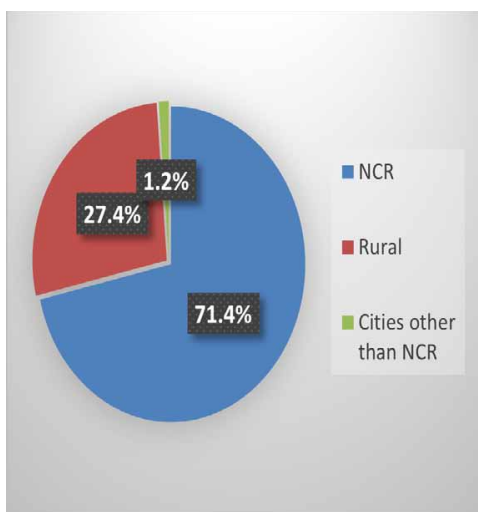


Figure 4. Respondent Type

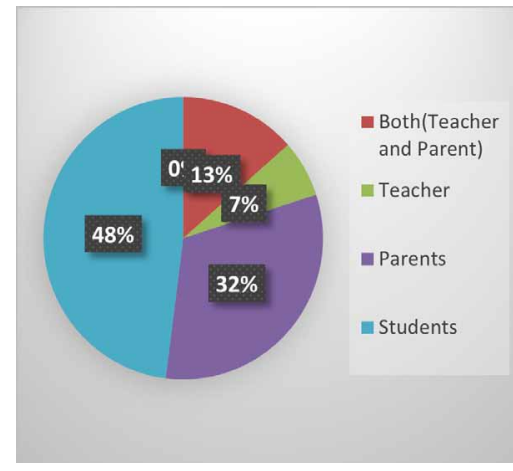

Figure 5. Distance between Tower and residence

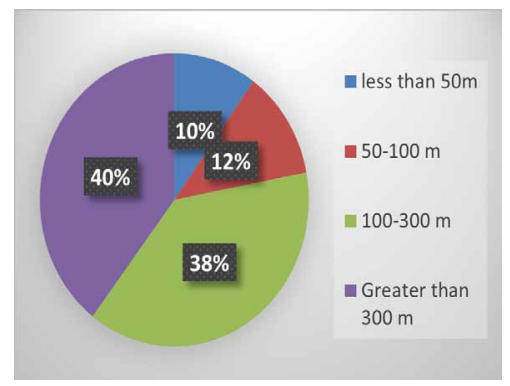

Figure 6. Awareness of Distance

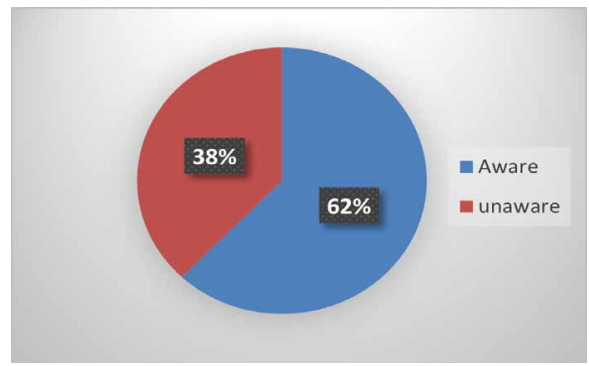

Figure 7. Usage of Mobile Handset

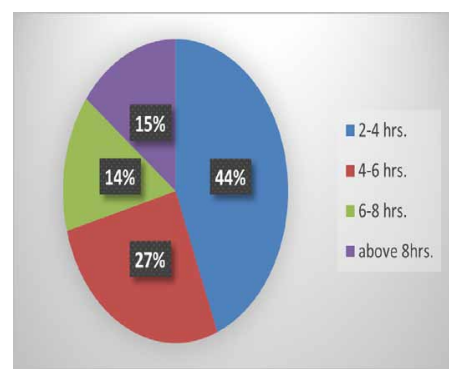


has also been found that $7.8 \%$ of the children (8-15 years) access internet above 8 hours due to their requirements which is not in case of 3-7 years children (Figure 10).

In the present scenario of COVID-19 pandemic the present survey also reflects its results to 94\% of the responders agree with the increase in their access to internet due to COVID-19 pandemic (Figure 11). It increased the internet usage at least by 2 hours, $41.5 \%$ and $13.4 \%$ of the responders had increased their internet usage duration by more than 6 hours (Figure 12). During the survey it has been observed that irrespective of gender 32\% people keep their cell phone is shirt pockets and rest keep in pant pocket 28\%, Purse/pouch $17 \%$ and hand $23 \%$ without knowing its biological harms (Figure 13). Although it should be kept away from the body like in purse/pouch which is the lowest number. It also comes with the harmful effects on the human being due to the EMF radiations as the

Figure 8. Awareness Details

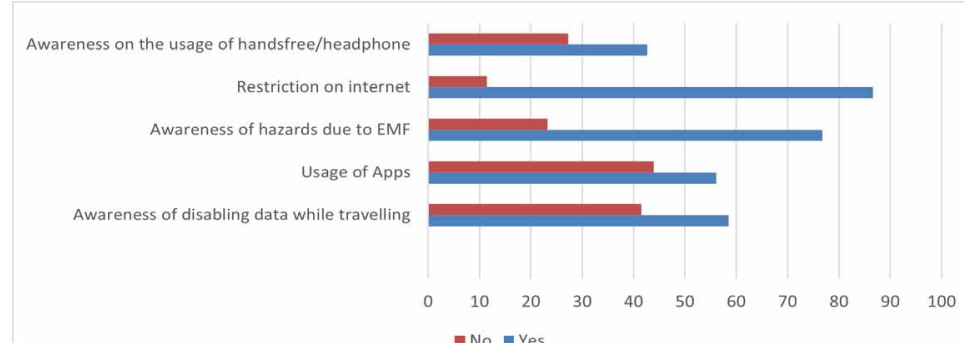

Figure 9. Disabling data and usage of handsfree

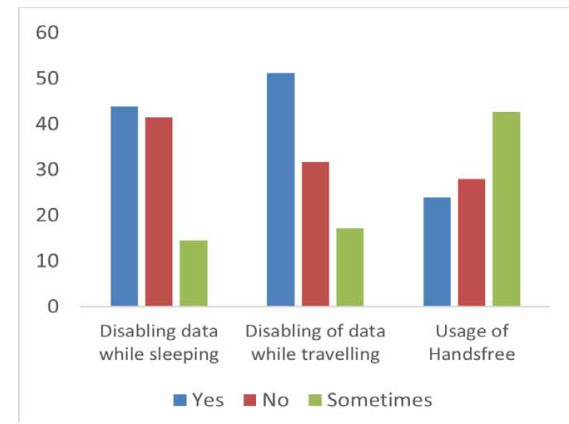

Figure 10. Usage of handsfree

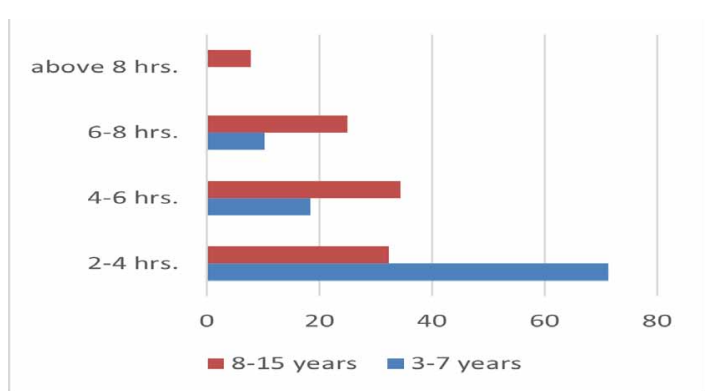


responders are developed with sleeplessness $34.1 \%$, headache $29.3 \%$, backache $20.7 \%$ and dizziness $12.2 \%$ along with hearing disturbances, heart diseases, anxiety, depression, nausea, breathing difficulty, earache, carcinoma, etc. (Figure 14). All these disturbances might be due to decreased immunity of individual by the excessive use of cell phones and their emitting EMF radiations.

\subsection{Findings of Survey}

Following are the key findings of survey specifically due to COVID-19:

- A huge increase of mobile usage in education

Figure 11. Increase in mobile usage due to COVID-19

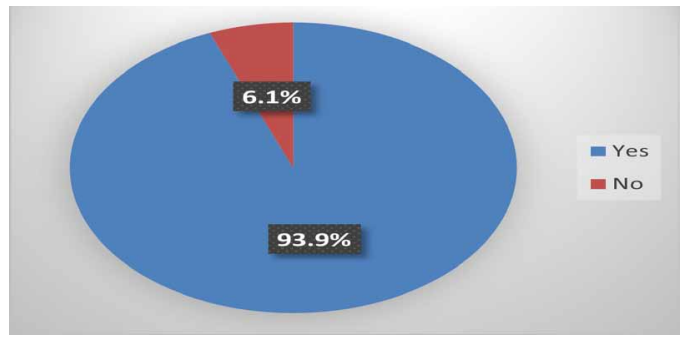

Figure 12. Average increase of usage of mobile during COVID-19

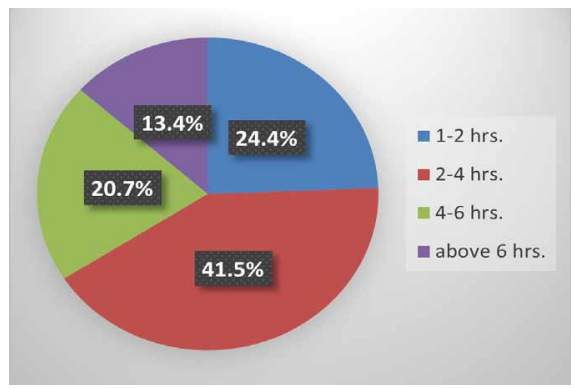

Figure 13. Site of keeping Cell phone

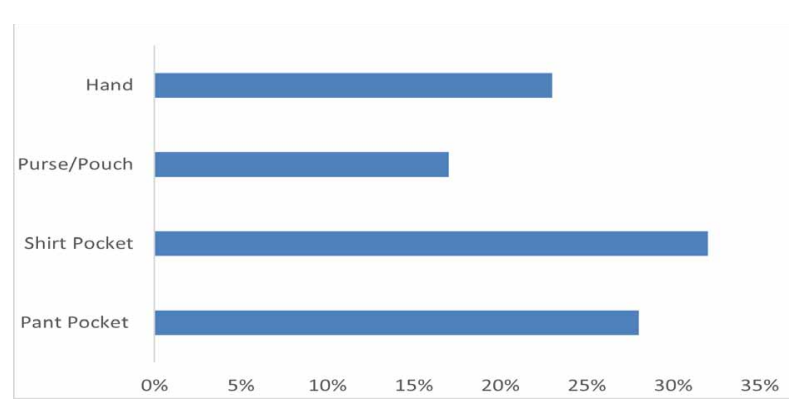




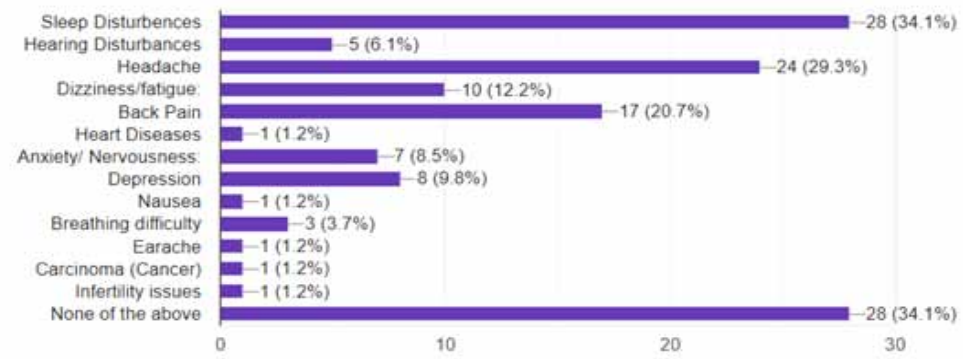

- Disease like- Headache back pain, heart related trouble, and hearing disturbance is increasing at a greater pace in people.

- People are less aware of when and how much mobile should be used

- Very few people know about the hazards caused by the mobile

\section{SUGGESTIONS AND FUTURE PROSPECTS}

In view of the above analysis this section provides few suggestive measures to avoid this harmful radiation caused due to cell phones. The present study emphasizes the necessity of strategies and policies to take precautionary measures concerning human exposure to electromagnetic fields.

\subsection{Government Regulations}

a. A proper layout of guidelines can be prepared from the scientific community and regulatory authorities in particular to give direction to academic institutions public as well as companies involved in this area.

b. Strong regulatory response from Government over cell phone usage so that there will be restriction on the number of SIM-cards issued to a single person which will limit the total EMF usage and the living beings will be protected from the hazardous effect of electromagnetic fields.

c. Cautionary remarks and protective measures are to be displayed with the cell phone during its sale and at points of sale.

d. Cell towers must be distanced from human settlements.

\subsection{Application of AI Techniques}

e. It will be helpful to estimate the amount of EMF radiations exposed to the user which will provide a cut-off usage of mobile phones by the techniques like Artificial Intelligence, machine learning or fuzzy logic. It may give a signal to the user so that he/she will be protected from any biological damage by limiting its further use.

f. Artificial Intelligence, machine learning or fuzzy logic techniques can be used for the early detection of the diseases caused by the EMF radiation considering the usage of mobile and the location of person's residence.

\subsection{Usage of Cell Phones}

a. It is always better to use Ethernet cable rather that Wi-Fi to avoid the radiation. 
b. When not in use EMF Sources are to be Kept at a distance.

c. A cell phone should never be put to your head.

d. Use headphones/ear phones for voice calls and listening anything from cell phones, speaker phone.

e. Before going to sleep mobile phones should be left in another room making the data off.

f. The cell phone should never be carried in a pocket or your bra, etc.

g. The phone should never be used while travelling except texting messages and emergencies as radiation levels are increased

h. Using shielding devices on computer screens, cellular phones and other EMF generating machines is essential.

i. The laptop should be used on battery power (not charging/plugged-in).

j. A wired keyboard and mouse should be used to decrease the exposure to EMF.

k. The computer or laptops should be kept a few feet away during using even not on the lap.

1. Wireless iPads are to be utilized are sparingly and streaming of video or music should not done with Wi-Fi.

\subsection{Awareness Programs}

Governments have to aware their people about usage of mobile phone the do's and don'ts, adding shielding to household wiring, circuit box, and transformers to reduce the exposure to EMFs.

\section{CONCLUSION AND FUTURE SCOPE}

The present study highlights the modernism forced mankind to adopt the online world in the recent condition of COVID-19 pandemic. The increased usage of internet in education raises the occurrence of harmful effects of the EMF radiations on academic society due to higher exposure to internet to face the present requirement of online classes in schools and colleges. The study throws light on the application of artificial techniques like machine learning, deep learning etc. for the assessment of EMF radiation induced untoward effects mainly targeting the genetic mutation leading to heart disorders, cancer, etc. The present survey shows all the students are enormously assessing internet due to the additional reason of COVID-19 pandemic. Increased duration of exposure to the electromagnetic fields or EMFs generated by $5 \mathrm{G}$ devices may not cause COVID-19, but the study shows it increases the susceptibility of the individual towards the occurrence ofCOVID-19 by decreasing immunity and increasing respiratory complications. The study also reflects the decreased recovery of COVID-19 if the EMF exposure will not be controlled. This analysis will be helpful for further studies and new investigations to evaluate the means to overcome these EMF-induced biological impacts more scientifically to cater the proper health of academic world along with the general public. It further elaborates the recent research on the benefits of these AI techniques for the early detection of diseases caused by the radiation. It will a boon in the field of medicine to add different management schemes for the EMF induced disorders along with the betterment of students for better utilization in their academic field. Through the analysis of the survey conducted many pertinent points have been observed one of the important factors is awareness about this harmful radiation. Few suggestions have been provided regarding the management of exposure to EMF radiation. The study can also be utilized for framing suitable policies along with regulations to minimize EMF exposures to the greatest degree possible without significant economic cost and disturbance. The target of the study will also be achieved by the socioeconomic benefits by alerting awareness among the users of mobile phones and internet about the precautions and management of their untoward effects. The outputs of the study is to aware and protect academic society from EMF-induced biohazards and adopt more protective measures like immune boosters for enhancing immunity and social distancing by the internet users to protect themselves from COVID-19 infection. 


\section{REFERENCES}

Aggarwal, S., Saluja, S., Gambhir, V., Gupta, S., \& Satia, S. P. S. (2020). Predicting likelihood of psychological disorders in PlayerUnknown's Battlegrounds (PUBG) players from Asian countries using supervised machine learning. Addictive Behaviors, 101, 106-112. doi:10.1016/j.addbeh.2019.106132 PMID:31704370

Ali, F., El-Sappagh, S., Islam, S. M. R., Kwak, D., Ali, A., Imran, M., \& Kwak, K. S. A. (2020). Smart healthcare monitoring system for heart disease prediction based on ensemble deep learning and feature fusion. Information Fusion, 63, 208-222. doi:10.1016/j.inffus.2020.06.008

Angelo, C. D., Costantini, E., Kamal, M. A., \& Reale, M. (2015). Experimental model for ELF-EMF exposure: Concern for human health. Saudi Journal of Biological Sciences, 22(1), 75-84. doi:10.1016/j.sjbs.2014.07.006 PMID:25561888

Atasoy, H., Gunal, M. Y., Atasoy, P., Elgund, S., \& Bugdayci, G. (2013). Immunopathologic demonstration of deleterious effects on growing rat testes of radiofrequency waves emitted from conventional Wi-Fi devices. Journal of Pediatric Urology, 9(2), 223-229. doi:10.1016/j.jpurol.2012.02.015 PMID:22465825

Avendano, C., Mata, A., Sanchez Sarmiento, C. A., \& Doncel, G. F. (2012). Use of laptop computers connected to internet through Wi-Fi decreases human sperm motility and increases sperm DNA fragmentation. Fertility and Sterility, 97(1), 39-45. doi:10.1016/j.fertnstert.2011.10.012 PMID:22112647

Beksaç, M. S., Durak, B., Özkan, O., Çakar, A. N., Balci, S., Karakaş, U., \& Laleli, Y. (1995). An artificial intelligent diagnostic system with neural networks to determine genetical disorders and fetal health by using maternal serum markers. European Journal of Obstetrics, Gynecology, and Reproductive Biology, 59(2), 131-136. doi:10.1016/0028-2243(94)02034-C PMID:7544745

Boumaiza, S., Bouharati, S., Bouzidi, A., Lalaoui, M., Boumaiza, S., Bouharati, S., Bouzidi, A., \& Lalaoui, M. (2015). Predicting Health Effects of Electromagnetic Pollution in Algeria Using Fuzzy Logic. International Journal of Public Health Research, 3(6), 352-356.

Campisi, A., Gulino, M., Acquaviva, R., Bellia, P., Raciti, G., Grasso, R., Musumeci, F., Vanella, A., \& Triglia, A. (2010). Reactive oxygen species levels and DNA fragmentation on astrocytes in primary culture after acute exposure to low intensity microwave electromagnetic field. Neuroscience Letters, 473(1), 52-55. doi:10.1016/j. neulet.2010.02.018 PMID:20156525

Coccia, M. (2020). Deep learning technology for improving cancer care in society: New directions in cancer imaging driven by artificial intelligence. Technology in Society, 60, 101-108. doi:10.1016/j.techsoc.2019.101198

Comlekci, S., Coskun, O., \& Kahriman, M. (2014). Fuzzy-Based Assessment of Health Hazards of a Reference Antenna. Arabian Journal for Science and Engineering, 39(4), 3095-3099. doi:10.1007/s13369-014-0953-6

Cummins, N., Matcham, F., Klapper, J., \& Schuller, B. (2020). Artificial intelligence to aid the detection of mood disorders, Artificial Intelligence in Precision Health. Concepts to Application, 16, 231-255.

Curcio, G. (2019). Human psychomotor performance under the exposure to mobile phones-like electromagnetic fields, advanced methodologies and technologies in network architecture. In Mobile Computing, and Data Analytics. IGI Global., doi:10.4018/978-1-5225-7598-6.ch067

Davis, A., Billick, K., Horton, K., Jankowski, M., Knoll, P., Marshall, J. E., Paloma, A., Palma, R., \& Adams, D. B. (2020). Artificial Intelligence and Echocardiography: A Primer for Cardiac Sonographers. Journal of the American Society of Echocardiography, 11(9), 1-9. doi:10.1016/j.echo.2020.04.025 PMID:32536431

Delhai, J., \& Montag, C. (2020). The compatibility of theoretical frameworks with machine learning analyses in psychological research. Current Opinion in Psychology, 36, 83-88. doi:10.1016/j.copsyc.2020.05.002 PMID:32563708

El-Bialy, N. S., \& Rageh, M. M. (2013). Extremely low-frequency magnetic field enhances the therapeutic efficacy of low-dose cisplatin in the treatment of Ehrlich carcinoma. BioMed Research International, 18, 93-102. doi:10.1155/2013/189352 PMID:23484088

Franzellitti, S., Valbonesi, P., Ciancaglini, N., Biondi, C., Contin, A., Bersani, F., \& Fabbri, E. (2010). Transient DNA damage induced by high-frequency electromagnetic fields (GSM $1.8 \mathrm{GHz}$ ) in the human trophoblast HTR8/SVneo cell line evaluated with the alkaline comet assay. Mutation Research, 683(1-2), 35-42. 
Garaj, V. V., Gajski, G., Pažanin, S., Sarolić, A., Domijan, A. M., Flajs, D., \& Peraica, M. (2011). Assessment of cytogenetic damage and oxidative stress in personnel occupationally exposed to the pulsed microwave radiation of marine radar equipment. International Journal of Hygiene and Environmental Health, 4(1), 59-65. doi:10.1016/j.ijheh.2010.08.003 PMID:20833106

Geoff, C., Sc, M. M. R., Mngt, M. A., Iqbal, B., \& Kiat, H. (2019). Intelligent Imaging: Radiomics and Artificial Neural Networks in Heart Failure. Journal of Medical Imaging and Radiation Sciences, 50(4), 571-574. doi:10.1016/j.jmir.2019.08.006 PMID:31588038

George, A. Z., Joseph, W. F., Motosko, C. C., \& Roger, S. H. (2020). Characterizing the role of dermatologists in developing artificial intelligence for assessment of skin cancer: A systematic review. Journal of the American Academy of Dermatology, 17, 23-29.

Guler, G., Tomruk, A., Ozgur, E., Sahin, D., Sepici, A., Altan, N., \& Seyhan, N. (2012). The effect of radiofrequency radiation on DNA and lipid damage in female and male infant rabbits. International Journal of Radiation Biology, 88(4), 367-373. doi:10.3109/09553002.2012.646349 PMID:22145622

Guosheng, L. G., Fan, W., Hui, L., \& Xiao, Z. (2020). The merging roles of artificial intelligence in cancer drug development and precision therapy. Biomedicine and Pharmacotherapy, 128, 1-10.

Ioan, F., Marius, L., \& Simona, D. (2019). A Fuzzy Approach for the Treatment of the Human Diseases Resulting from Exposure to Electromagnetic Fields. Studies in Informatics and Control, 28(3), 299-308. doi:10.24846/ v28i3y201906

Islam, M. R., \& Mazumder, T. (2010). Mobile application and its global impact. IACSIT International Journal of Engineering and Technology, 10(6), 72-78.

Jabbari, P., \& Rezaei, N. (2019). Artificial Intelligence and Immunotherapy. Expert Review of Clinical Immunology, 50(7), 689-691. doi:10.1080/1744666X.2019.1623670 PMID:31157571

Jason, R. J., McCallum, C., \& Sinton, D. (2019). Deep learning for the classification of human sperm. Computers in Biology and Medicine, 11, 103-112.

Javadi, S., Abolghasem, S., \& Mirroshandel, A. (2019). novel deep learning method for automatic assessment of human sperm images. Computers in Biology and Medicine, 109, 182-194. doi:10.1016/j.compbiomed.2019.04.030 PMID:31059902

Jouni, F. J., Abdolmaleki, P., \& Ghanati, F. (2012). Oxidative stress in broad bean (Viciafaba L.) induced by static magnetic field under natural radioactivity. Mutation Research, 741(1-2), 116-121. doi:10.1016/j. mrgentox.2011.11.003 PMID:22108253

Kadampur, M. A., \& Riyaee, S. (2020). Skin cancer detection: Applying a deep learning based model driven architecture in the cloud for classifying dermal cell images. Informatics in Medicine Unlocked, 18, 100-108. doi:10.1016/j.imu.2019.100282

Karaboytcheva, M. (2020). Effects of $5 G$ wireless communication on human health. https://www.europarl.europa. eu/RegData/etudes/BRIE/2020/646172/EPRS_BRI(2020)646172_EN.pdf

Karaca, E., Durmaz, B., Altug, H., Yildiz, T., Guducu, C., Irgi, M., Koksal, M. G., Ozkinay, F., Gunduz, C., \& Cogulu, O. (2012). The genotoxic effect of radiofrequency waves on mouse brain. Journal of Neuro-Oncology, 106(1), 53-58. doi:10.1007/s11060-011-0644-z PMID:21732071

Khalil, A., Al-Adhammi, M., Al-shara, B., Gagaa, M., Rawshdeh, A., \& Alshamli, A. (2012). Histological and ultrastructural analyses of male mice exposed to mobile phone radiation. Journal of Toxicological Review, 1, 1-6.

Kilic, A. (2020). Artificial Intelligence and Machine Learning in Cardiovascular Health Care. The Annals of Thoracic Surgery, 109(5), 1323-1329. doi:10.1016/j.athoracsur.2019.09.042 PMID:31706869

Kivrak, E. G., Yurt, K. K., Kaplan, A. A., Alkan, I., \& Altun, G. (2017). Effects of electromagnetic fields exposure on the antioxidant defense system. Journal of Microscopy and Ultrastructure, 5(4), 167-176. doi:10.1016/j. jmau.2017.07.003 PMID:30023251

Kora, P., Meenakshi, K., Swaraja, K., Rajani, A., \& Islam, M. K. (2019). Detection of Cardiac arrhythmia using fuzzy logic. Informatics in Medicine Unlocked, 17, 100-107. doi:10.1016/j.imu.2019.100257 
Kosalay, I. (2010). Estimation of RF Electromagnetic Levels around TV Broadcast Antennas Using Fuzzy Logic. IEEE Transactions on Broadcasting, 56(1), 24-35. doi:10.1109/TBC.2009.2035944

Lanillos, P., Olivia, D., Philippsen, A., Yamashita, Y., Nagai, Y., \& Cheng, G. (2020). A review on neural network models of schizophrenia and autism spectrum disorder. Neural Networks, 122, 338-363. doi:10.1016/j. neunet.2019.10.014 PMID:31760370

Levitt, B. B., \& Lai, H. (2010). Biological effects from exposure to electromagnetic radiation emitted by cell tower base stations and other antenna arrays. Environmental Reviews, 18(NA), 369-395. doi:10.1139/A10-018

Liu, G. D., Li, Y. C., Zhang, W., \& Zhang, L. (2020). A Brief Review of Artificial Intelligence Applications and Algorithms for Psychiatric Disorders. Engineering, 6(4), 462-467. doi:10.1016/j.eng.2019.06.008

Lolea, M., \& Dzitac, S. (2018). A few categories of electromagnetic field problems treated through Fuzzy Logic. IOP Conference Series. Materials Science and Engineering, 294, 12-23. doi:10.1088/1757-899X/294/1/012093

Lueken, U., \& Hahn, T. (2014). Personalized mental health: Artificial intelligence technologies for treatment response prediction in anxiety disorders. Personalized Psychaitry, 12, 201-213.

Luukkonen, J., Liimatainen, A., Juutilainen, J., \& Naarala, J. (2020). Induction of genomic instability, oxidative processes, and mitochondrial activity by $50 \mathrm{~Hz}$ magnetic fields in human SH-SY5Y neuroblastoma cells. Mutation Research, 760, 33-41. doi:10.1016/j.mrfmmm.2013.12.002 PMID:24374227

Malik, J. A. (2020). Effects of Electromagnetic Radiation of Mobile Phones on the Human Brain. In Mobile Devices and Smart Gadgets in Medical Science. IGI Global. doi:10.4018/978-1-7998-2521-0.ch006

Miller, A. B., Sears, M. E., Morgan, L. L., Davis, L. L., Hardell, L., Oremus, M., \& Soskolne, C. L. (2019). Risks to Health and Well-Being From Radio-Frequency Radiation Emitted by Cell Phones and Other Wireless Devices. Frontiers in Public Health, 7, 1-10. doi:10.3389/fpubh.2019.00223 PMID:31457001

Okechukwu, C.E. (2020) Effects of radiofrequency electromagnetic field exposure on neurophysiology. Advances in Human Biology, 10(1), 6-10.

Oscar, C. A., Carlos, R., Fernández, S., Jorge, P. I., Hugo, R. Z., Karla, B. M., Maria, A. A. M., Carlos, M. S., Sharon, S. C., Beatriz, E., Dominguez, M., Pimvan, D. H., \& Luis, E. J. O. (2020). Integrating the STOP-BANG Score and Clinical Data to Predict Cardiovascular Events After Infarction: A Machine Learning Study. Chest, $12,23-31$.

Pachuau, L., \& Pachuau, Z. (2014). Study of cell tower radiation and its health hazards on human body. IOSR Journal of Applied Physics, 6(1), 1-6.

Pang, T., Wong, J. H. D., Nag, W. L., \& Chan, C. S. (2020). Deep learning radiomics in breast cancer with different modalities: Overview and future. Expert Systems with Applications, 158, 113-116. doi:10.1016/j. eswa.2020.113501

Perconti, P., \& Plebe, A. (2020). Deep learning and cognitive science. Cognition, 203, 104-115. doi:10.1016/j. cognition.2020.104365 PMID:32563082

Prakash, K. L., Siddique, M. I., \& Kumar, P. R. (2016). Effects of Mobile Tower Radiations on human health: A case study from Bangalore. Elixir Pollution, 96, 41305-41307.

Raj, S., \& Masood, S. (2020). Analysis and Detection of Autism Spectrum Disorder Using Machine Learning Techniques. Procedia Computer Science, 167, 994-1004. doi:10.1016/j.procs.2020.03.399

Rosado, M. M., Simkó, M., Mattsson, M. O., \& Pioli, C. (2018). Immune-Modulating Perspectives for Low Frequency Electromagnetic Fields in Innate Immunity. Frontiers in Public Health, 6, 85-91. doi:10.3389/ fpubh.2018.00085 PMID:29632855

Sasa, D. M., Branislav, D., \& Djordje, M. S. (2019). A fuzzy-measurement algorithm for assessing the impact of EMF on health. Nuclear Technology \& Radiation Protection, 34, 18-19.

Sechopoulos, I., Teuwen, J., \& Mann, R. (2020). Artificial intelligence for breast cancer detection in mammography and digital breast tomosynthesis: State of the art. Seminars in Cancer Biology. PMID:32531273 
Sharma, S., \& Singh, B. (2014). WiMAX Network for Capacity and Coverage Assessment. Wireless Personal Communications, 75(2), 1573-1586. doi:10.1007/s11277-013-1438-8

Shen, H., Hu, Y., Liu, X., Jiang, Z., \& Ye, H. (2020). Role of cardiovascular color doppler imaging information technology under artificial intelligence neural network in the diagnosis of septic shock patients. Neuroscience Letters, 56(1), 36-43. doi:10.1016/j.neulet.2020.135199 PMID:32585254

Singh, A., Singh, N., Jindal, T., Muñoz, A. R., \& Dutta, M. K. (2020). A novel pilot study of automatic identification of EMF radiation effect on brain using computer vision and machine learning. Biomedical Signal Processing and Control, 57, 12-18. doi:10.1016/j.bspc.2019.101821

Singh, A. P., \& Kaur, R. (2014). Electromagnetic fields: Biological implications on various life forms. International Journal of Bioassays, 3(04), 2030-2040.

Singh, S., \& Kapoor, N. (2014). Health Implications of Electromagnetic Fields, Mechanisms of Action, and Research Needs. Advances in Biology, 24, 1-24. doi:10.1155/2014/198609

Srivastava, S., Pant, M., \& Agarwal, R. (2020). Role of AI techniques and Deep learning in analyzing the critical health conditions. International Journal of Systems Assurance, 11(3), 350-365. doi:10.1007/s13198-019-00863-0

Srivastava, S., Pant, M., \& Agrawal, N. (2018). Psychology of Adolescents: A Fuzzy Logic Analysis. International Journal of Systems Assurance, 9(1), 66-81. doi:10.1007/s13198-016-0472-9

Stafford, I. S., Kellermann, M., Mossotto, E., Beattie, R. M., MacArthur, B. D., \& Ennis, S. (2020). A systematic review of the applications of artificial intelligence and machine learning in autoimmune diseases. NPJ Digital Medicine, 3(1), 30-38. doi:10.1038/s41746-020-0229-3 PMID:32195365

Sultangaliyeva, I., Beisenova, R., Tazitdinova, R., Abzhalelov, A., \& Khanturin, M. (2020). The influence of electromagnetic radiation of cell phones on the behavior of animals. Veterinary World, 13(3), 49-55. doi:10.14202/ vetworld.2020.549-555 PMID:32367963

Taylor, D. G., \& Levin, M. A. (2014). Predicting mobile app usage for purchasing and information-sharing. International Journal of Retail \& Distribution Management, 42(8), 759-774. doi:10.1108/JJRDM-11-2012-0108

Tognola, G., Bonato, M., Chiaramello, E., Fiocchi, S., Magne, I., Souques, M., Parazzini, M., \& Ravazzani, P. (2019). Use of Machine Learning in the Analysis of Indoor ELF MF Exposure in Children. International Journal of Environmental Research and Public Health, 16(7), 12-20. doi:10.3390/ijerph16071230 PMID:30959870

Vijay, S., \& Choudhary, M. P. (2017). Study on Health Effects of Mobile Tower Radiation on Human Beings. International Research Journal of Engineering and Technology, 4(11), 15-48.

Wang, P., Song, Q., Li, Y., Lv, S., Wang, J., \& Zhang, H. H. (2020). Cross-task extreme learning machine for breast cancer image classification with deep convolutional features. Biomedical Signal Processing and Control, 57, 38-48. doi:10.1016/j.bspc.2019.101789

Wang, S., \& Wiart, J. (2020). Sensor-Aided EMF Exposure Assessments in an Urban Environment Using Artificial Neural Networks. International Journal of Environmental Research and Public Health, 17(9), 30-52. doi:10.3390/ijerph17093052 PMID:32353961

Wong, K. K. K., Fortino, G., \& Abbott, D. (2020). Deep learning-based cardiovascular image diagnosis: A promising challenge. Future Generation Computer Systems, 110, 802-811. doi:10.1016/j.future.2019.09.047

Xu, B., Kocyigit, D., Grimm, R., Griffin, B. P., \& Cheng, F. (2020). Applications of artificial intelligence in multimodality cardiovascular imaging: A state-of-the-art review. Progress in Cardiovascular Diseases, 19(3), 28-33. doi:10.1016/j.pcad.2020.03.003 PMID:32201286

Yang, H., Li, T., Hu, X., Wang, F., \& Zou, Y. (2014). A survey of Artificial Immune System Based Intrusion Detection. Recent Advancement in Computer and Software Technology, 156790, 11-22. doi:10.1155/2014/156790 PMID:24790549

Zhang, L., Dong, D., Zhang, W., Hao, X., Fang, M., Wang, S., Li, W., Liu, Z., Wang, R., Zhou, J., \& Tian, J. (2020). A deep learning risk prediction model for overall survival in patients with gastric cancer: A multicenter study. Radiotherapy and Oncology: Journal of the European Society for Therapeutic Radiology and Oncology, 150, 73-80. doi:10.1016/j.radonc.2020.06.010 PMID:32540334 
Dr Sanjita Das is working as Professor and HOD, Pharmacology at Noida Institute of Engineering and Technology (Pharmacy Institute), Greater Noida, India. She was awarded her PhD from Birla Institute of Engineering and Technology, Mesra, Ranchi, India in 2008. Her area of research is psychopharmacology and ethnopharmacology.

Shilpa Srivastava has a Ph.D from Uttarakhand Technical University Dehradun in Computer Science \& Engineering(2016) with more than 18 years of teaching experience. Qualified NET exam in the year 2015. Presently serving as an Associate Professor in Christ (Deemed to be University) Delhi NCR Campus. Her areas of interest include Application of Soft Computing in medical domain, Theory of Computation, Algorithms and ehealth services. She has publications in indexed journals \& presented papers in conferences of national and international repute.

Aprna Tripathi has served in different academic and administrative roles in various academic institutions since 2002. Most recently, she served GLA university Mathura (2017- 2019). She earned her PhD in computer science from MNNIT Allahabad (2015), M. Tech. from Banasthali University, Rajasthan (2009) and MCA from HBTI Kanpur (now known as HBTU) (2002). She did her graduation from Kanpur University in 1998. She has published several papers in reputed journals and her area of specialization is software engineering, Software Testing and Data Analytics. She authored a book " Component Based Systems: Estimating Effects Using Soft Computing Techniques" with CRC Publication.

Dr Saumya Das is working as Associate Professor at Noida Institute of Engineering and Technology (Pharmacy Institute), Greater Noida, India. She was awarded her PhD from Birla Institute of Engineering and Technology, Mesra, Ranchi, India in 2016. Her area of research is ethnopharmacology.

Dr Saumya Das is working as Associate Professor at Noida Institute of Engineering and Technology (Pharmacy Institute), Greater Noida, India. She was awarded her PhD from Birla Institute of Engineering and Technology, Mesra, Ranchi, India in 2016. Her area of research is ethnopharmacology. 